\title{
Dynamics of enhancers in myeloid antigen presenting cells upon LPS stimulation
}

\author{
Alexis Vandenbon ${ }^{1,2^{*}}$, Shunsuke Teraguchi ${ }^{3}$, Osamu Takeuchi ${ }^{4}$, Yutaka Suzuki ${ }^{5}$, Daron M Standley ${ }^{1 *}$ \\ From The 25th International Conference on Genome Informatics (GIW/ISCB-Asia) \\ Tokyo, Japan. 15-17 December 2014
}

\begin{abstract}
Background: Recent studies have underscored the role of enhancers in defining cell type-specific transcriptomes. Cell type-specific enhancers are bound by combinations of shared and cell type-specific transcription factors (TFs). However, little is known about combinatorial binding of TFs to enhancers, dynamics of TF binding following stimulation, or the downstream effects on gene expression. Here, we address these questions in two types of myeloid antigen presenting cells (APCs), macrophages and dendritic cells (DCs), before and after stimulation with lipopolysaccharide (LPS), a potent stimulator of the innate immune response.

Results: We classified enhancers according to the combination of TFs binding them. There were significant correlations between the sets of TFs bound to enhancers prior to stimulation and expression changes of nearby genes after stimulation. Importantly, a set of enhancers pre-bound by PU.1, C/EBP $\beta$, ATF3, IRF4, and JunB was strongly associated with induced genes and binding by stimulus-activated regulators. Our classification suggests that transient loss of ATF3 binding to a subset of these enhancers is important for regulation of early-induced genes. Changes in TF-enhancer binding after stimulation were correlated with binding by additional activated TFs and with the presence of proximally located enhancers.
\end{abstract}

Conclusions: The results presented in this study reveal the complexity and dynamics of TF- enhancer binding before and after stimulation in myeloid APCs.

\section{Background}

The control of gene expression plays a central role in nearly all biological processes. Transcription initiation is regulated on a number of levels, including modification of epigenetic markers and recruitment of RNA polymerase by transcription factors (TFs) [1]. Enhancers can be functionally defined as short genomic regions which regulate expression of genes, often over long distances. It is well established that enhancers play a key role in the regulation of gene expression [2,3]. Recent developments in sequencing techniques have enabled high-resolution investigation of a wide variety of histone modifications, and their functional annotation $[4,5]$. Enhancers have been shown to be marked by high amounts of the histone modification

\footnotetext{
* Correspondence: alexisvdb@ifrec.osaka-u.ac.jp; standley@ifrec.osaka-u.ac.jp 'Laboratory of Systems Immunology, Immunology Frontier Research Center, Osaka University, Suita, 565-0871, Japan

Full list of author information is available at the end of the article
}

H3K4me1 [5,6], and recent estimates suggest that several hundred thousand enhancers exist in the human and mouse genomes $[6,7]$.

However, despite the identification of master regulators in several cell types, and technical advances in molecular biology, much remains obscure. For example, the degree to which cell type-specific enhancers are dependent solely on pioneer factors or master regulators is poorly understood. Specific combinations of TFs that bind to enhancers might play key roles in regulating genes involved in biological processes, but which TF combinations control which processes is generally unknown. Finally, the dynamics in the binding of regulatory elements following stimulation, as well as the interactions between these elements, have not been well described.

Here, we address these issues using myeloid APCs (macrophages and DCs). These cells represent a first line of defence against pathogens as part of the innate immune 
system, and play a role in the subsequent activation of the adaptive immune system. A number of recent studies have emphasized a central role of the lineage-determining Ets family member PU.1 in defining cell type-specific enhancers in APCs. Binding of PU.1, in combination with a small set of cell type-restricted, lineage-determining factors, is necessary for defining macrophage-specific H3K4me1-marked regions during differentiation, and the binding of PU.1 in macrophages co-occurs with the binding of stress-inducible TFs, such as NF- $\kappa$ B and IRFs $[8,9]$. It has also been shown that in terminally differentiated macrophages so-called latent enhancers become bound by stimulus-activated and lineage-determining TFs only after stimulation [10]. A similar central role of PU.1 as a master regulator defining cell type-specific enhancers and regulating the response to immune stimuli has been shown in DCs [11].

The myeloid APCs analysed in this study present a useful system for integrative analysis since there is an abundance of genome-wide data available for these cells. Here, we generated RNA-seq data as a measure of gene expression and transcription start site sequencing (TSS-seq) data [12] as a measure of transcription initiation events, and analysed it in combination with publicly available ChIPseq data for various histone modifications [8,13], $24 \mathrm{TFs}$ and RNA polymerase II (Pol2) [11]. We used these data sets to define enhancers on a genome-wide level, and to carry out a detailed analysis of enhancer-TF interactions. We found that regions with enhancer-like features were bound by a variety of sets of principal TFs. Specifically, we found that one class of enhancers was bound even before stimulation by PU.1, C/EBP $\beta$, ATF3, IRF4, and JunB (here referred to as "class $\mathrm{H}_{1}$ enhancers"). This class was strongly associated with genes that have induced expression following immune stimulation with LPS. After stimulation, the same enhancers were then preferentially bound by activated TFs, such as NF- $\kappa \mathrm{B}$, IRFs, and STAT family TFs. This suggests that the behaviour of genes after stimulation is, to some degree, already decided by the TFs binding to nearby enhancers before stimulation. On the other hand, we also found a considerable degree of change in TF binding to enhancers after stimulation. One change, the transient loss after LPS stimulation of ATF3 binding at $\mathrm{H}_{1}$ enhancers, appears to control a set of early induced genes. Our results suggest that such changes might be governed by interactions between activated TFs and principal binding TFs, as well as between proximally located enhancer pairs.

\section{Methods}

We refer to Figure 1 for a flowchart of the main steps of this study. Below is a detailed description of the steps and results.

\section{Acquisition and processing of high-throughput sequencing data}

For TSS-seq data analysis, we prepared peritoneal exudate cells from C57BL/ 6 mice 3 days after injection with $2 \mathrm{ml} 4 \%$ thioglycolate medium (Sigma). Cells attached on the culture dish were stimulated with $100 \mathrm{ng} / \mathrm{ml}$ LPS from S. Minnesota Re595 (Sigma) for $4 \mathrm{~h}$, followed by the extraction of total RNAs with Trizol (Life Technologies). TSS-seq was performed on these RNAs using the procedure described in [12]. RNA-seq data was taken from macrophages at three time points $(0 \mathrm{~h}, 1 \mathrm{~h}$, and $4 \mathrm{~h}$ after stimulation with LPS). The short-read sequence archive data are registered in the DNA Data Bank of Japan (DDBJ) under accession nos. [DDBJ:DRA001207] and [DDBJ:DRA001208]. Reads were mapped to the mm9 genome using ELAND [14] and uniquely mapped reads with at most 2 mismatches to the reference genome were used for further analysis.

For ChIP-seq data, public ChIP-seq reads for H3K4me3 (0h: GSM470558, 4h: GSM470559), H3K27me3 (0h: GSM470560, 4h: GSM470561), and H3K4me1 (0h: GSM487452) taken from bone marrow-derived macrophages (BMDMs) $[8,13]$ were downloaded from the NCBI Gene Expression Omnibus and mapped to the $\mathrm{mm} 9$ genome using SOAP2 [15]. ChIP-seq data for PU.1 (GSM487450), C/EBP $\beta$ (GSM537985), and Pol2 (GSM470562) was processed in the same way.

\section{Classification of genomic regions and definition of enhancer regions}

In order to define potentially functional genomic regions from TSS-seq and ChIP-seq for H3K27me3, H3K4me1, and H3K4me3, the number of mapped tags in the mouse genome was counted in bins of 200 bps in steps of 200 bps. For the TSS-seq reads this was done in a strand-specific way. The position of mapped ChIP-seq reads was shifted by 75 bp in the 3' direction. Significant peaks were detected using a Poisson distribution-based $\mathrm{p}$ value, using a threshold $\mathrm{p}$ value of $1 \mathrm{e}-6$. Regions containing significant levels of one or more features were merged if they were less than 500 bps separated. The weighted average of ppm reads was used to define the central bin of each region, and the 10 bins upstream and downstream of this central bin (total of 21 bins, $4.2 \mathrm{~kb}$ ). Regions containing mapped TSS-seq reads were oriented so that the majority of tags were located on the "+" strand. We excluded regions containing significant levels of mapped TSS-seq reads but lacking any histone modifications. Such loci were especially enriched in 3' UTR regions, and might represent reads originated by recapping, or by genuine transcription initiation [16,17]. This procedure resulted in 165,446 genomic regions associated with significant levels of one or more epigenetic or transcriptomic features. 


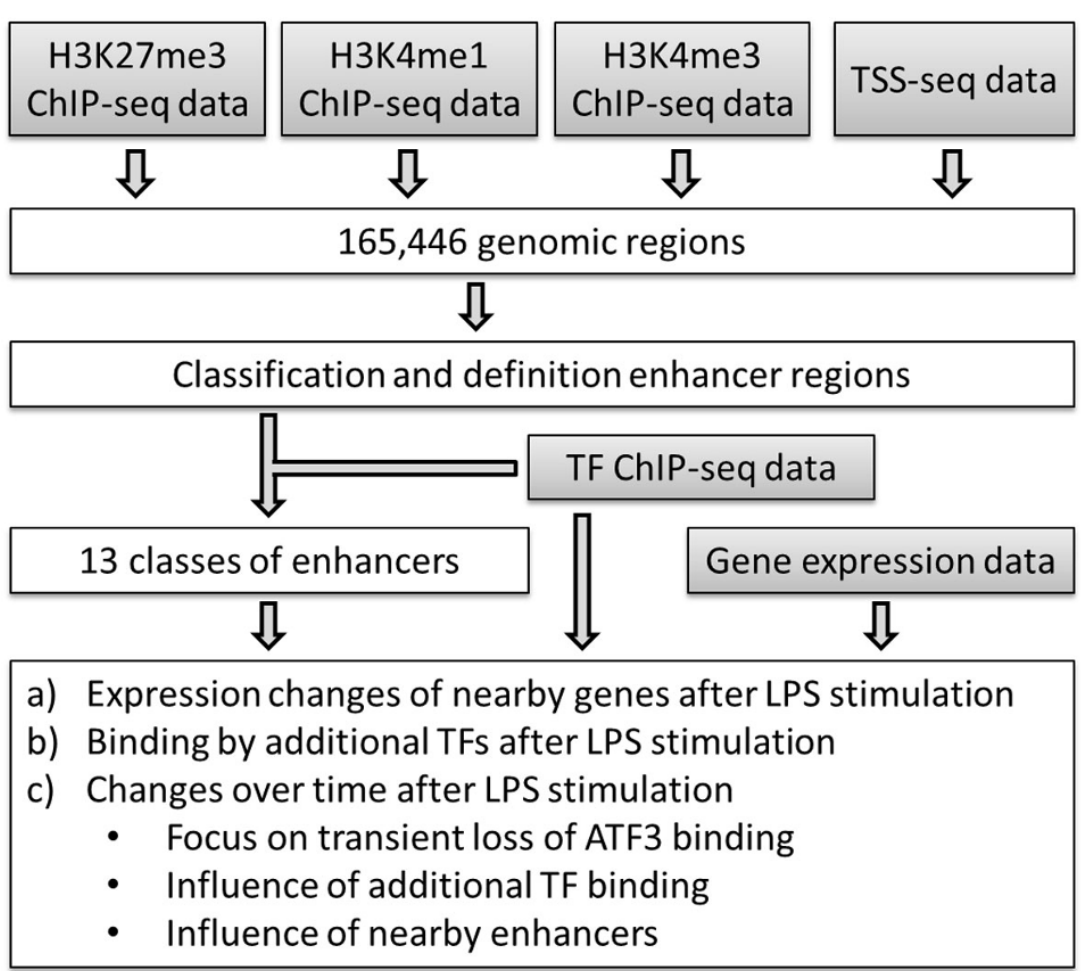

Figure 1 Flowchart of the main steps in this study. Step 1 is the identification of genomic regions marked by one or more histone modifications or transcription initiation events. In step 2 genomic regions are clustered according to their features and enhancer regions are defined. In step 3, enhancers are further classified into 13 classes according to the pre-stimulation binding by six principal TFs. We perform various more detailed analyses on these 13 classes of enhancers in step 4, including analysis of gene expression of nearby genes, binding by additional TFs, and changes in binding by principal TFs after stimulation. Main input data are marked in grey.

Regions were marked as overlapping with TSS regions, 5' UTRs, 3' UTRs, exonic regions, or intronic regions, in this order of preference, if they overlapped with these features based on Refseq annotations as available in the UCSC database $[18,19]$. Regions not overlapping with any of these features were marked as intergenic. $\mathrm{K}$ - means clustering was used to identify enhancer-like genomic regions according to histone modifications and transcription initiation events (Figure 2).

\section{Analysis of TF binding to enhancer regions}

Genome-wide binding regions of 24 TFs (Ahr, Atf3, Cebpb, Ctcf, E2f1, E2f4, Egr1, Egr2, Ets2, Hif1a, Irf1, Irf2, Irf4, Junb, Maff, Nfkb1, PU1, Rel, Rela, Relb, Runx1, Stat1, Stat2, Stat3) in bone marrow-derived dendritic cells (BMDCs) before and after stimulation with LPS [11] were obtained from the Genome Expression Omnibus (accession number GSE36104). We used ChIP-seq-based peak scores as reported in the original study [11], as an indication of TF binding throughout the genome. For each TF at each available time point, we associated peak scores with the center of the reported peak regions, and assigned them to the corresponding bins of $200 \mathrm{bps}$ for all 165,446 regions defined above. Bins not including a peak region center received a score of 0 .

The overall binding tendencies of TFs to enhancers was evaluated using the highest peak score assigned to the central 11 bins of 200 bps (corresponding to the region $-1.1 \mathrm{~kb}$ to $+1.1 \mathrm{~kb}$ surrounding the region center). Table 1 shows the percentage of enhancer regions having a score higher than or equal to 26.9, the threshold score used in original study [11], for each TF at time point $0 \mathrm{~h}$.

\section{Clustering of enhancers by the binding of principal TFs}

Enhancers were clustered using the binding by PU.1, C/EBP 3 , CTCF, Atf3, Irf4, and Junb at time point 0h. For each of these 6 TFs, the highest score over the central 11 bins of 200 bps was assigned to each enhancer. Scores higher than 26.9 were set to 26.9. Enhancers were clustered using k-means clustering using these scores. The optimal number of clusters was estimated to be 13 using the Gap statistic method [20].

For the analysis of changes over the time points after stimulation, the same 13 clusters based on the time point oh clustering were used to cluster enhancer regions. This 


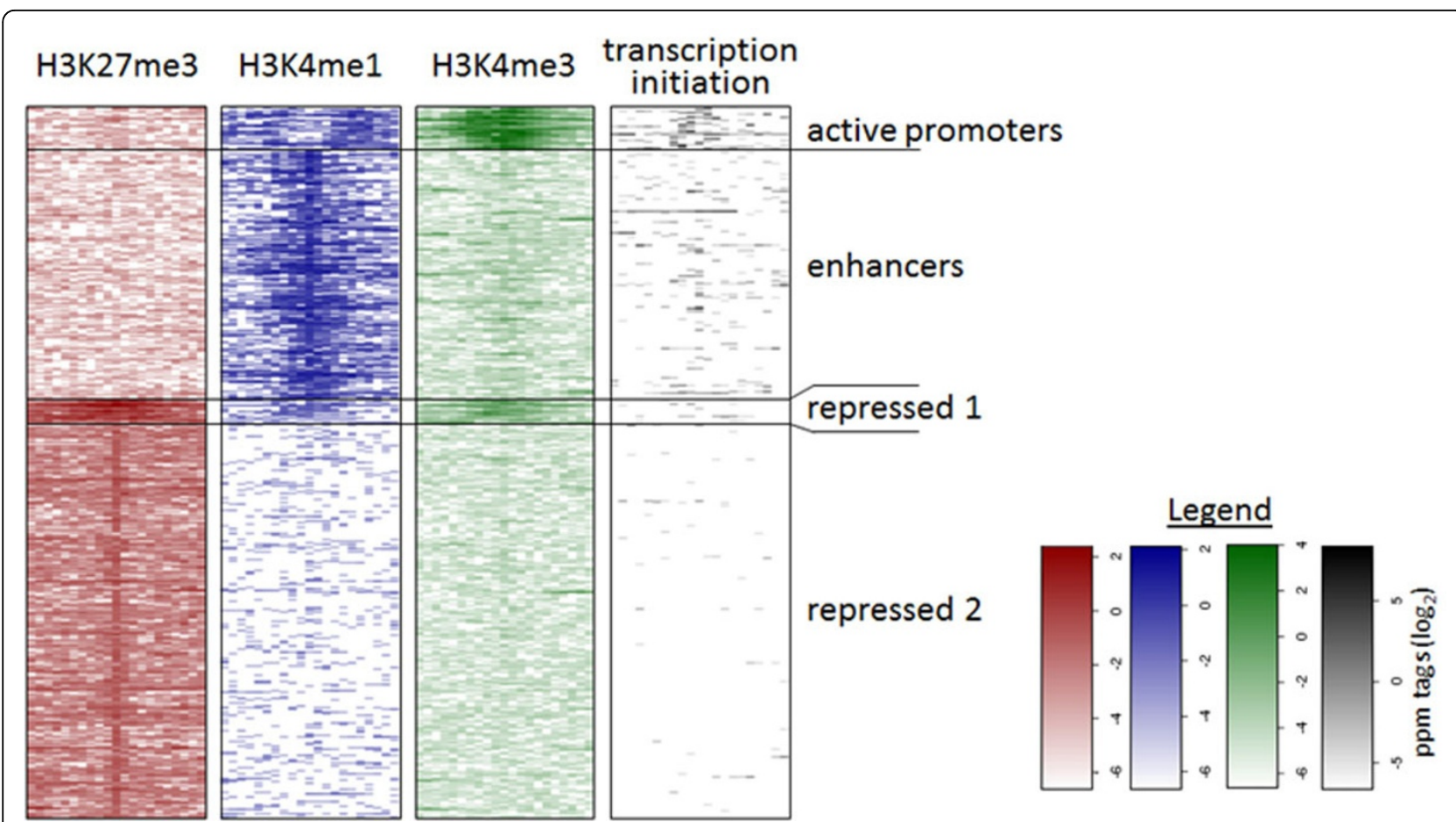

Figure 2 Clustering of genomic regions and definition of enhancer regions. Heatmap representing the clustering of genomic regions into 4 classes according to their H3K27me3, H3K4me1, H3K4me3, and transcription initiation profile.

was done by assigning regions to the most proximal cluster, in terms of Euclidian distance.

\section{Gene expression analysis}

From the RNA-seq data taken from macrophages at three time points $(0 \mathrm{~h}, 1 \mathrm{~h}$, and $4 \mathrm{~h}$ after stimulation with LPS), RPKM (reads per kilobase per million reads) values were calculated for all genes, and subjected to quantile normalization. We identified 2,188 genes with at least 3-fold differential expression over the three time points, and at least one time point with RPKM higher than 1 . These genes were clustered into 4 classes ("early induction", "late induction", "gradual induction", and "repression") based on their $\log (\mathrm{RPKM})$ values using hierarchical clustering. In addition, we defined a class of genes with unchanged

Table 1 Principal TFs binding active promoters and enhancer regions.

\begin{tabular}{ll}
\hline Regulator & Bound enhancers (\%) \\
\hline PU.1 & 38.0 \\
C/EBP $\beta$ & 26.0 \\
JunB & 14.1 \\
IRF4 & 12.1 \\
CTCF & 8.9 \\
ATF3 & 8.4 \\
\hline
\end{tabular}

The percentage of bound enhancers for a set of 6 principal TFs is shown, based on ChIP-seq data (11). TFs bound to more than $5 \%$ enhancers are shown. expression after stimulation as the 5,000 genes with the smallest fold changes over the three time points.

Micro-array gene expression data for ATF3 knock-out (KO) and wild-type (WT) BMDMs was obtained from ArrayExpress (ID: E-TABM-102) [21]. RMA normalized probe intensities were averaged over duplicate experiments, and gene expression levels were calculated by averaging over probes.

\section{Assigning genes to enhancer regions}

Enhancer regions were naively assigned to the most proximal gene, based on the distance in bases between the center of the enhancer region and the gene's TSS. Multiple enhancers can be assigned to the same gene.

For the analysis of associations between enhancer classes and sets of genes with a particular expression profile (see section Gene expression analysis), we first counted for each set of genes, the number of assigned enhancer regions of each enhancer class. Next, a Z score was calculated based on this count and the average and standard deviation of expected counts obtained from 100 sets of enhancers with randomly shuffled enhancer class indices.

\section{Further supporting analysis and data availability}

Distances between pairs of enhancers were calculated as the distance in bases between their centers. GC content and $\mathrm{CpG}$ scores in regions were calculated in bins of 
200 bps. TFBS motif enrichment was performed as described in Additional file 1 (Supplementary Material).

The short-read sequence data obtained for this research are registered in the DDBJ under accession nos. [DDBJ:DRA001207] (RNA-seq data) and [DDBJ: DRA001208] (TSS-seq data).

\section{Results}

Identification of enhancer regions using epigenetic markers and transcription initiation events

Given the known chromatin signature associated with active and inactive promoters and enhancer regions, we detected 165,446 genomic regions based on statistically significant enrichment of epigenetic markers, H3K4me3, H3K27me3, and H3K4me1 (obtained from ChIP-seq data using BMDMs) along with transcription initiation events (from newly obtained TSS-seq data from thioglycollateelicited peritoneal macrophages). To identify enhancer regions among these candidate regions, we used k-means clustering which resulted in 4 distinct clusters (Figure 2 and Materials and Methods section). The cluster ("active promoters"; 9,586 regions) with high levels of transcription initiation events also showed high levels of H3K4me3 and lower levels of H3K4me1 (Supplementary Figure S1A in Additional file 1), fitting well with the known characteristics of active promoters. The "enhancer" cluster (58,370 regions), on the other hand, lacked high levels of transcription initiation and H3K4me3, but contained high levels of H3K4me1, and thus is consistent with previous findings. There is a clear difference in the profile of the H3K4me1 marker; in the promoter group $\mathrm{H} 3 \mathrm{~K} 4 \mathrm{me} 1$ is limited to regions surrounding the strong H3K4me3 peak, which is absent in the enhancer cluster (Supplementary Figure S1A in Additional file 1). Other properties of the "active promoter" and "enhancer" regions are also consistent with known characteristics

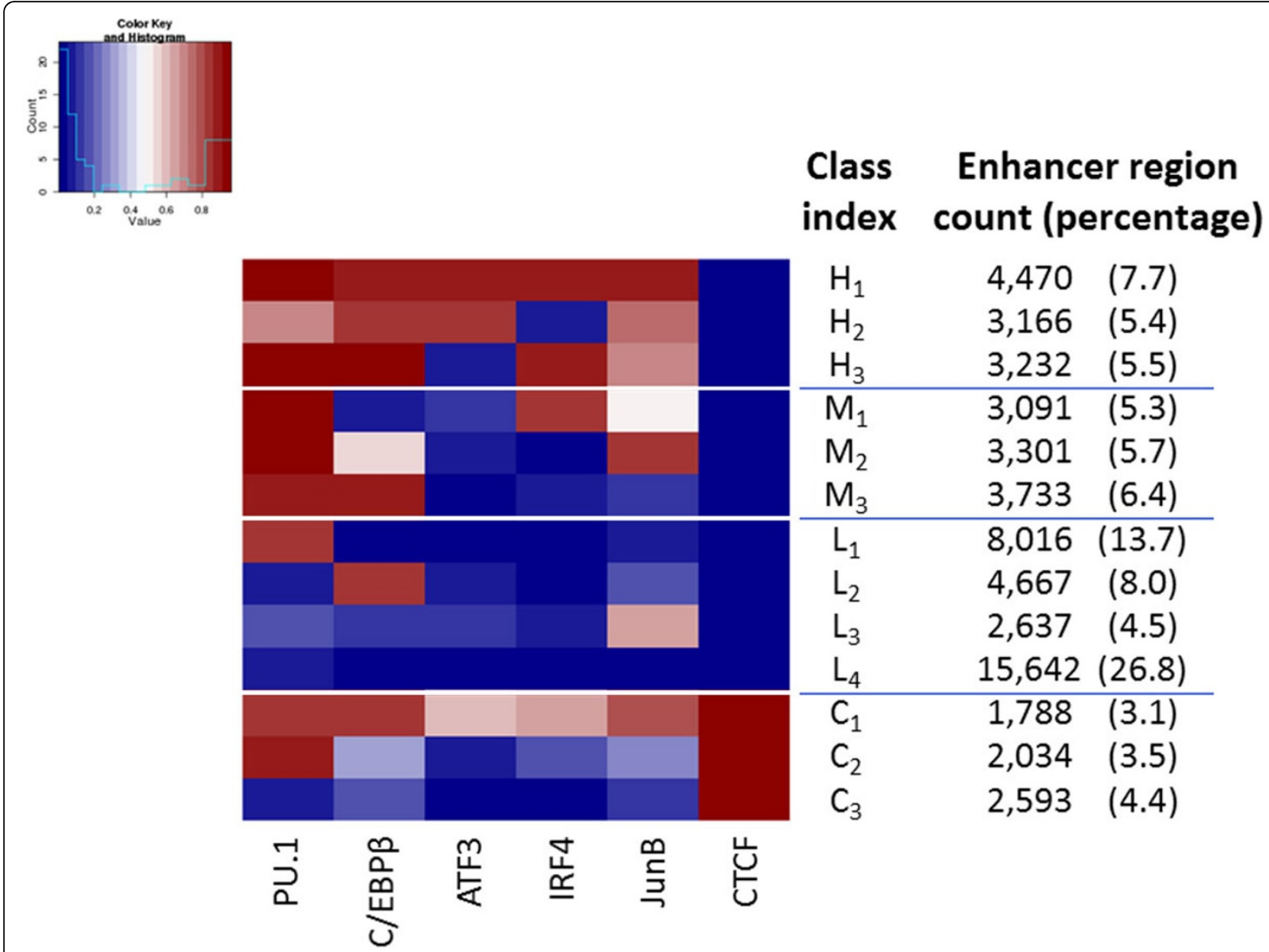

Figure 3 Clustering of enhancer regions according to bound TFs. For the 13 enhancer classes (rows) the average normalized peak score for the 6 principal TFs (columns) is shown. Colors represent the average rates of binding of each TF in each class of enhancers, with red, white, and blue colors indicating high, intermediate, and low rates of binding, respectively. Columns on the right of the heatmap show for each class the index, the number of regions in the class in unstimulated cells, and the corresponding percentage of the total set of enhancers. 
(see Supplementary Material and Supplementary Figures S1B-C in Additional file 1). The two remaining clusters were marked by high levels of the repressive marker H3K27me3, either in combination with low levels of H3K4me1 and H3K4me3 ("repressed 1"; 5,394 regions) or by the repressive marker $\mathrm{H} 3 \mathrm{~K} 27 \mathrm{me} 3$ alone ("repressed 2 "; 92,096 regions). For the remainder of this paper we will focus on the analysis of the "enhancer" regions.

\section{Clustering of enhancer regions according to binding by 6 principal transcription factors}

We verified the binding of TFs to enhancer regions in unstimulated cells using ChIP-seq data for a set of 24 TFs that are highly expressed in BMDCs [11] (Materials and Methods section). We found that in addition to PU. 1 and C/EBP $\beta$, a number of other TFs are also associated with a substantial fraction of enhancers (Table 1 and Supplementary Table S1 in Additional file 1). In particular, Atf3, Irf4, and Junb were significantly bound to more than $5 \%$ of enhancers and promoters. Interestingly, the insulator-binding protein CTCF was associated with $8.9 \%$ of enhancers (and $22.3 \%$ of active promoters), consistent with observations made in recent studies $[7,22,23]$. In order to reveal the pattern of combinatorial TF binding to enhancers and analyze their distinctive properties, we further clustered enhancer regions in terms of binding by 6 principal TFs (PU.1, C/EBP $\beta$, ATF3, IRF4, JunB, and CTCF). Again, using k- means clustering, with the optimal number of clusters based on the Gap statistic method [20] (Materials and Methods section), enhancers were clustered into 13 classes (Figure 3 ). We roughly divided these 13 classes of enhancers into 4 groups according to the number of principal TFs binding them. The 13 classes were specified here using a 2-character index, with the first index reflecting the number of principal TF binding them; H (Highly bound), M (Medium bound), L (Lowly bound), and C (bound by CTCF). The second index indicates a further subdivision and ranged from 1-4. This clustering allows us to make several observations. First, there exists considerable variety in the sets of TFs binding enhancer regions. Class $\mathrm{H}_{1}$ enhancers are bound by PU.1, C/EBP $\beta$, ATF3, IRF4, and JunB, while class $\mathrm{L}_{4}$ enhancers are bound by none of the 6 principal TFs. Compared to class $\mathrm{H}_{1}$ enhancers, class $\mathrm{H}_{2}$ and $\mathrm{H}_{3}$ enhancers lack IRF4 and ATF3 binding, respectively. Other classes are bound by other combinations of TFs. Second, most of the enhancer classes are bound by PU.1 and C/EBP $\beta$ as a pair or in combination with other principal TFs. These enhancers fit well with the notion that macrophage- and DC-specific enhancers are defined by PU.1 as a master regulator in combination with $C / E B P \beta$ as a lineage-specific TF. However, in addition to a large subset of enhancers being bound by none of the 6 principal
TFs (class L4; 15,642 regions; 26.8\%), a number of classes lack binding by PU.1 (L2), or C/EBP $\left(\mathrm{L}_{1}\right.$ and $\left.M_{1}\right)$, or both $\left(L_{3}\right.$ and $\left.C_{3}\right)$. The existence of classes $L_{3}$ and $\mathrm{C}_{3}$ suggest that JunB or CTCF are able to bind $\mathrm{H} 3 \mathrm{~K} 4 \mathrm{me} 1$-marked regions even in the absence of master regulator PU. 1 and $C / E B P \beta$. Classes $L_{1}$ and $L_{2}$ suggest that H3K4me1-marked regions can be bound by either PU.1 or C/EBP $\beta$ in the absence of any of the other principal TFs. TFBS sequence motif analysis confirmed many of the observed binding tendencies (see Supplementary Material and Supplementary Figure S2 in Additional file 1). Together, these results suggest considerable variety in TF binding at enhancer regions, and that a substantial fraction of enhancers differ in their TF binding from "typical" myeloid APC enhancers.

\section{$\mathrm{H}_{1}$ class enhancers are especially associated with induced} genes and binding by TFs activated after LPS stimulation

To evaluate potentially different biological functions of distinct enhancer classes, we investigated and compared a number of features of all classes. First, we evaluated correlations between the presence of enhancers of certain classes and gene expression patterns in nearby genes. We clustered genes with differential expression following LPS stimulation into 4 sets; early induction, late induction, gradual induction, and repression (Supplementary Fig. S3 in Additional file 1), and we also defined a set of 5000 genes with no change in expression as a negative control. For each set of genes we examined the class of nearby enhancers, and identified significant associations (see Materials and Methods section). We found that $\mathrm{H}_{1}$ enhancers were strongly associated with early induction genes (188 regions observed vs 90 expected; Z-score = 11.2) (Figure 4A), or induced genes in general (704 regions observed vs 493 expected; $Z$-score $=10.5$ ). This is consistent with the observation made by Garber et al. [11]. The rest of highly bound enhancers $\left(\mathrm{H}_{2}\right.$ and $\left.\mathrm{H}_{3}\right)$, and also a set of lowly bound enhancer $\left(\mathrm{L}_{3}\right)$, which are defined mainly by JunB binding, showed associations with induced genes. $C_{1}$ enhancers, on the other hand, which are bound by CTCF, had no strong association with induced genes. We observed that $\mathrm{L}_{4}$ enhancers were associated with genes lacking expression change $(4,073$ regions observed vs 3,712 expected; Z-score $=7.5$ ), and had a corresponding tendency not to be associated with early induction genes (206 regions observed vs 315 expected; Z-score = -6.6). Second, we found differences in TF binding (as measured by ChIP-seq) induced by LPS stimulation (Figure 4B). Here too we found that enhancers of class $\mathrm{H}_{1}$ were preferentially bound by NF- $\kappa$ B subunits (NFKB1, Rel, Rela, and Relb). This was true even before stimulation but the difference became greater after stimulation: of the 4,470 $\mathrm{H}_{1}$ enhancer regions, 2,026 regions (45.3\%) were bound by Rela 2 hours after 


\section{A \\ Enhancer classes

\begin{tabular}{|c|c|c|c|c|c|c|c|c|c|c|c|c|c|}
\hline & $\mathrm{H}_{1}$ & $\mathrm{H}_{2}$ & $\mathrm{H}_{3}$ & $\mathrm{M}_{1}$ & $\mathrm{M}_{2}$ & $\mathrm{M}_{3}$ & $\mathrm{~L}_{1}$ & $L_{2}$ & $\mathrm{~L}_{3}$ & $\mathrm{~L}_{4}$ & $\mathrm{C}_{1}$ & $\mathrm{C}_{2}$ & $\mathrm{C}_{3}$ \\
\hline early & $\begin{array}{r}188 \\
90 \\
\end{array}$ & $\begin{array}{r}87 \\
65 \\
\end{array}$ & $\begin{array}{r}84 \\
64 \\
\end{array}$ & $\begin{array}{c}67 \\
61 \\
\end{array}$ & $\begin{array}{r}89 \\
66 \\
\end{array}$ & $\begin{array}{c}72 \\
74 \\
\end{array}$ & \begin{tabular}{|c|}
135 \\
163 \\
\end{tabular} & $\begin{array}{c}75 \\
93 \\
\end{array}$ & $\begin{array}{c}66 \\
53 \\
\end{array}$ & \begin{tabular}{|c|}
206 \\
315 \\
\end{tabular} & $\begin{array}{r}41 \\
35 \\
\end{array}$ & $\begin{array}{c}31 \\
40 \\
\end{array}$ & $\begin{array}{c}31 \\
53 \\
\end{array}$ \\
\hline late & $\begin{array}{c}372 \\
302 \\
\end{array}$ & $\begin{array}{r}234 \\
211 \\
\end{array}$ & $\begin{array}{r}240 \\
216 \\
\end{array}$ & $\begin{array}{r}236 \\
208 \\
\end{array}$ & $\begin{array}{r}231 \\
220 \\
\end{array}$ & $\begin{array}{r}249 \\
250 \\
\end{array}$ & $\begin{array}{c}500 \\
540 \\
\end{array}$ & $\begin{array}{c}363 \\
313 \\
\end{array}$ & $\begin{array}{r}200 \\
175 \\
\end{array}$ & $\begin{array}{c}921 \\
1042 \\
\end{array}$ & $\begin{array}{r}115 \\
120 \\
\end{array}$ & $\begin{array}{c}118 \\
139 \\
\end{array}$ & $\begin{array}{r}133 \\
176 \\
\end{array}$ \\
\hline gradu & $\begin{array}{c}144 \\
100 \\
\end{array}$ & $\begin{array}{c}88 \\
70 \\
\end{array}$ & $\begin{array}{r}97 \\
73 \\
\end{array}$ & $\begin{array}{c}63 \\
69 \\
\end{array}$ & $\begin{array}{c}64 \\
73 \\
\end{array}$ & $\begin{array}{c}82 \\
82 \\
\end{array}$ & \begin{tabular}{|c}
154 \\
180 \\
\end{tabular} & $\begin{array}{c}118 \\
104 \\
\end{array}$ & $\begin{array}{c}86 \\
58 \\
\end{array}$ & $\begin{array}{r}276 \\
349 \\
\end{array}$ & $\begin{array}{r}47 \\
40 \\
\end{array}$ & $\begin{array}{c}32 \\
47 \\
\end{array}$ & $\begin{array}{c}52 \\
58 \\
\end{array}$ \\
\hline unchan & $\begin{array}{c}895 \\
1053 \\
\end{array}$ & $\begin{array}{r}687 \\
756 \\
\end{array}$ & $\begin{array}{r}750 \\
766 \\
\end{array}$ & $\begin{array}{c}696 \\
736 \\
\end{array}$ & $\begin{array}{r}788 \\
783 \\
\end{array}$ & $\begin{array}{r}876 \\
884 \\
\end{array}$ & $\begin{array}{r}1900 \\
1902 \\
\end{array}$ & $\begin{array}{r}1065 \\
1108 \\
\end{array}$ & $\begin{array}{r}631 \\
626 \\
\end{array}$ & $\begin{array}{r}4073 \\
3712 \\
\end{array}$ & $\begin{array}{r}376 \\
423 \\
\end{array}$ & $\begin{array}{r}486 \\
478 \\
\end{array}$ & $\begin{array}{r}617 \\
612 \\
\end{array}$ \\
\hline epres & $\begin{array}{r}262 \\
272\end{array}$ & $\begin{array}{c}190 \\
193\end{array}$ & $\begin{array}{r}211 \\
198\end{array}$ & $\begin{array}{c}183 \\
190\end{array}$ & $\begin{array}{r}171 \\
200 \\
\end{array}$ & $\begin{array}{r}253 \\
228\end{array}$ & $\begin{array}{c}533 \\
490 \\
\end{array}$ & $\begin{array}{c}285 \\
287\end{array}$ & $\begin{array}{c}150 \\
161\end{array}$ & $\begin{array}{c}932 \\
959 \\
\end{array}$ & $\begin{array}{c}119 \\
109\end{array}$ & $\begin{array}{c}131 \\
124\end{array}$ & $\begin{array}{c}150 \\
159 \\
\end{array}$ \\
\hline
\end{tabular}

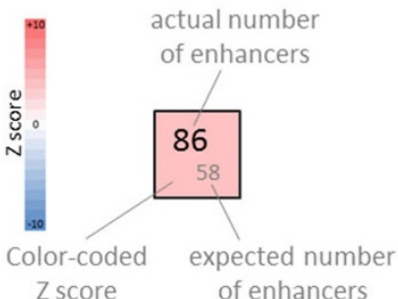

B
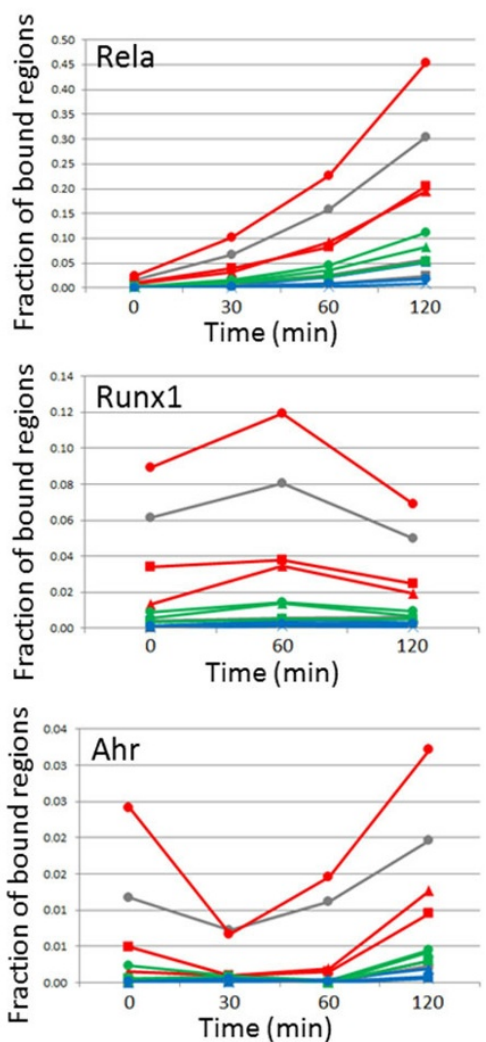
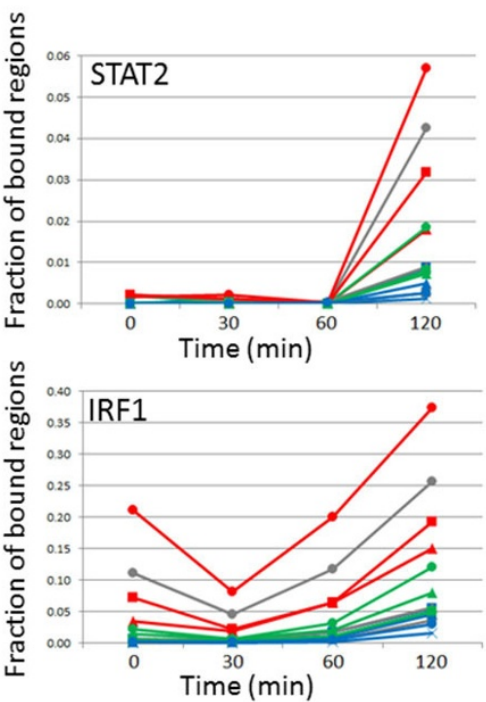

$\begin{array}{ll}\rightarrow \mathrm{H}_{1} & \rightarrow \mathrm{L}_{1} \\ \rightarrow \mathrm{H}_{2} & \rightarrow \mathrm{L}_{2} \\ \rightarrow \mathrm{H}_{3} & \rightarrow-\mathrm{L}_{3} \\ \rightarrow \mathrm{M}_{1} & \rightarrow \mathrm{L}_{4} \\ -\mathrm{M}_{2} & \rightarrow \mathrm{C}_{1} \\ -\mathrm{M}_{3} & \rightarrow \mathrm{C}_{2} \\ & \rightarrow-C_{3}\end{array}$

Figure 4 Properties of enhancer classes. (A) Figure showing the counts of enhancer regions per class (columns) associated with genes (rows) with (from top to bottom) early induction, late induction, gradual induction, no change, and repressed expression following LPS stimulation. Number in grey are expected counts based on random permutations. The colour code represents corresponding Z scores. (B) For Rela, STAT2, Runx1, IRF1, and Ahr, the fractions of bound enhancer regions per class are shown at different time points. 
stimulation (424 regions expected; Z-score $=88.1$ ). A similar tendency was seen for STAT1, STAT2, and STAT3 binding. Although there was virtually no binding prior to stimulation, 255 enhancers of class $\mathrm{H}_{1}(5.7 \%)$ were bound by STAT2 (54 regions expected; Z-score = 29.3) 2 hours after stimulation. Other transcription factors also had a strong preference to bind to $\mathrm{H}_{1}$ enhancers, both before and after stimulation. These include Ahr, IRF1, RUNX1, Egr2, and Maff (Figure 4B and data not shown). Similar but weaker observations were made for enhancer classes $\mathrm{H}_{2}$ and $\mathrm{H}_{3}$, but also $\mathrm{C}_{1}$ regions. On the other hand, enhancers of classes $L_{1}$ and $L_{4}$ tended to lack binding by any of the investigated TFs (Figure 4B and data not shown).

Together, the above results indicate that enhancers can be separated into several classes based on their binding by a set of principal TFs in unstimulated cells, and that the classification defines to a large extent their binding by other TFs even after stimulation as well as changes in expression of nearby genes after stimulation. Our results also suggest that enhancers that are highly bound, in particular class $\mathrm{H}_{1}$, play a more important role in the regulation of transcription in response to immune stimulation.

\section{Dynamics of enhancer classes following LPS stimulation}

The above results imply that the binding by a few principal TFs to enhancers prior to stimulation controls the behaviour of nearby genes after LPS stimulation. However, it is also possible that there is considerable dynamics in enhancer classes themselves after stimulation. In immune cells in particular, binding of the principal TFs to enhancers might be influenced by stimulation. To investigate the nature and extent of such changes in principal TF binding, we used the same classifiers derived prior to stimulation to classify enhancers based on their TF binding patterns at 30,60 , and 120 mins after stimulation by LPS.

Our results suggest that enhancers experience extensive changes in the binding by the principal TFs following stimulation (Supplementary Fig. S4 and Supplementary Table $\mathrm{S} 2$ in Additional file 1). Some of the class transitions involving class $\mathrm{H}_{1}$ enhancers are shown in Figure 5. During the first 30 minutes following stimulation, 1,021 regions (23\%) change from class $\mathrm{H}_{1}$ to $\mathrm{H}_{3}$ (losing ATF3 binding), resulting in a drop from 4,470 to $3,318 \mathrm{H}_{1}$ regions. A further 904 out of 3,318 remaining $\mathrm{H}_{1}$ regions (27\%) switch to $\mathrm{H}_{2}$ in the following 30 minutes (losing IRF4 binding). However, between 60 and 120 minutes following stimulation a change in the opposite direction occurs, with $1,597 \mathrm{H}_{2}$ regions and $466 \mathrm{H}_{3}$ regions changing to class $\mathrm{H}_{1}$ regions, bringing the final count to 5,342 regions. This includes $3,362(75.2 \%)$ of the original $\mathrm{H}_{1}$ regions.

These results illustrate that the classification of enhancers is not static, and that enhancers are able to gain and lose binding by one or more of the principal TFs following stimulation, which, in our analysis, is reflected by class transitions.

\section{$\mathrm{H}_{1}$ enhancers that transiently lose ATF3 binding following LPS stimulation are associated with early transiently induced genes}

As an illustration of the biological relevance of our enhancer classification and their changes over time, we focus here on one of the frequent changes: the transient loss of ATF3 binding at $\mathrm{H}_{1}$ enhancers at time point $0.5 \mathrm{~h}$, with a restoration of ATF3 binding at $1 \mathrm{~h}$, resulting in a change of $\mathrm{H}_{1} \rightarrow \mathrm{H}_{3} \rightarrow \mathrm{H}_{1}$. Of the $4,470 \mathrm{H}_{1}$ enhancers, 511 follow this pattern. One example is an enhancer located about $38 \mathrm{~kb}$ upstream of the gene $\mathrm{Cxcl1}$, which is illustrated in Figure 6A. This gene encodes a member of the CXC subfamily of chemokines, and plays a role in the acute inflammatory response through the recruitment of neutrophils to the site of infection [24]. Both RNA-seq data (not shown) and microarray data [25] show that Cxcl1 transcription is strongly induced at an early stage after LPS stimulation (Figure 6B and Supplementary Fig. S5A in Additional file 1). ATF3 has been shown to be a negative regulator in the TLR4 signalling pathway through the recruitment of histone deacetylases [25]. However, a potential regulatory role of the transient loss of ATF3 binding at enhancer regions after TLR activation in the regulation of early (and transiently) induced genes has not been described before.

The 511 enhancers transiently losing ATF3 binding are enriched around LPS-induced genes in general, but in particular in regions proximal to 141 early induced genes (28 enhancers vs 10.4 expected, Z score 5.8, Supplementary Fig. S6A in Additional file 1) and 113 transiently induced genes at time point $1 \mathrm{~h}$ (genes with a more than 2 -fold higher RPKM at $1 \mathrm{~h}$ than at both $0 \mathrm{~h}$ and $4 \mathrm{~h}$ ) (24 enhancers vs 7.6 expected, Z score 6.0, Supplementary Fig. S6B in Additional file 1). This enrichment is stronger than that of other subsets of $\mathrm{H}_{1}$ enhancers after LPS stimulation (not shown). These results suggest that the transient loss of ATF3 at these enhancers plays a role in the regulation of a subset of early and transiently induced genes. This hypothesis is supported by the enrichment of these enhancers around 111 genes that have a higher expression in a ATF3-/- KO BMDMs compared to WT BMDMs (11 enhancers vs 5.6 expected, Z score 2.2, Supplementary Fig. S6C in Additional file 1).

The above observations also fit well with the interactions between ATF3 and histone deacetylases, as suggested by Gilchrist et al. [25]. Acetylation of histones results in a more relaxed chromatin structure, increasing the accessibility of regions to TF binding, while deacetylation has the opposite effect. Higher levels of ATF3 binding might thus result in an increase of histone acetylation and in higher 

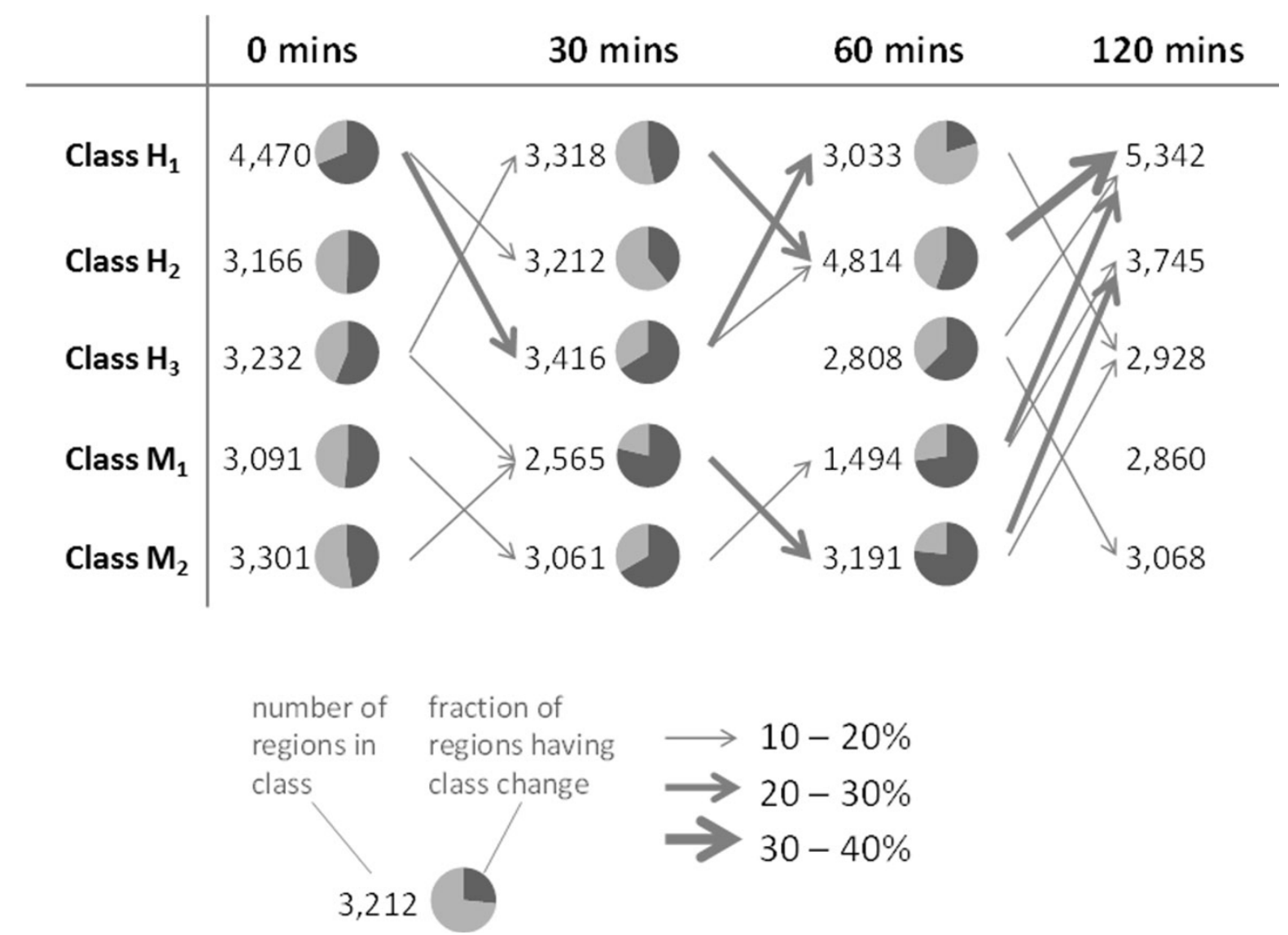

Figure 5 Dynamics in enhancer classes following LPS stimulation. For five enhancer classes $(H 1, H 2, H 3, M 1$, and $M 2)$ class transitions following stimulation are shown, with arrows indicating frequent transitions and the arrow thickness representing the frequency of the transition. Number indicate the number of enhancers belonging to each enhancer class at each time point, and the pie charts represent the fraction of enhancers in each class at each time point making or not making a class transition.

transcription initiation rates through the binding of additional TFs. In the case of Cxcl1, the loss of ATF3 at the region around $-38 \mathrm{~kb}$ coincides with binding by Rela (a component of NF- $\kappa \mathrm{B}$ ) and the induction of $\mathrm{Cxcl1}$ transcription (Figure 6B and Supplementary Fig. S5A in Additional file 1). One hour after stimulation, ATF3 binding is restored, Rela binding decreases, and gene expression reaches a plateau, followed by dropping levels of mRNA. Probe intensities of Cxcl1 (3 probes, each with 3 replicates) after LPS stimulation are on average 2- to 4-fold higher in the ATF3 KO compared to WT cells (Figure 6B and Supplementary Fig. S5A in Additional file 1). Similar higher expression in the ATF3 KO was observed for other early-induced genes having a nearby enhancer following the $\mathrm{H}_{1} \rightarrow \mathrm{H}_{3} \rightarrow \mathrm{H}_{1}$ pattern (Supplementary Fig. S5B in Additional file 1).

TF binding changes associated with enhancer class dynamics following stimulation

Little is known about the forces that influence TF binding at enhancers over time after stimulation of cells. Here, we examined two factors: the binding of other TFs that are only activated after stimulation, and inter-enhancer interactions.

We investigated the binding of TFs to regions where enhancer class transitions occur, and found several examples of activated TFs whose binding is correlated with enhancer class transitions. For example, enhancers of class $\mathrm{H}_{1}$ which change to $\mathrm{H}_{3}$ (thus losing binding by ATF3) tend to have lower levels of binding by Rela and IRF1 compared to regions that retain an $\mathrm{H}_{1}$ profile (Supplementary Fig. S7 in Additional file 1). They have lower Runx1 binding both before and after stimulation, and 120 mins. after stimulation they tend to be not bound by STAT family TFs (data not shown).

On the other hand, enhancers of class $\mathrm{H}_{3}$ which change to class $\mathrm{H}_{1}$ (thus gaining binding by ATF3) between 0 and 30 mins. or between 30 and 60 mins. following stimulation show a tendency to gain binding by Rela at the time when the enhancer class transition occurs (Figure 7A). Enhancers changing from class $\mathrm{H}_{3}$ to $\mathrm{H}_{1}$ between 60 and 120 mins. on the other hand, 


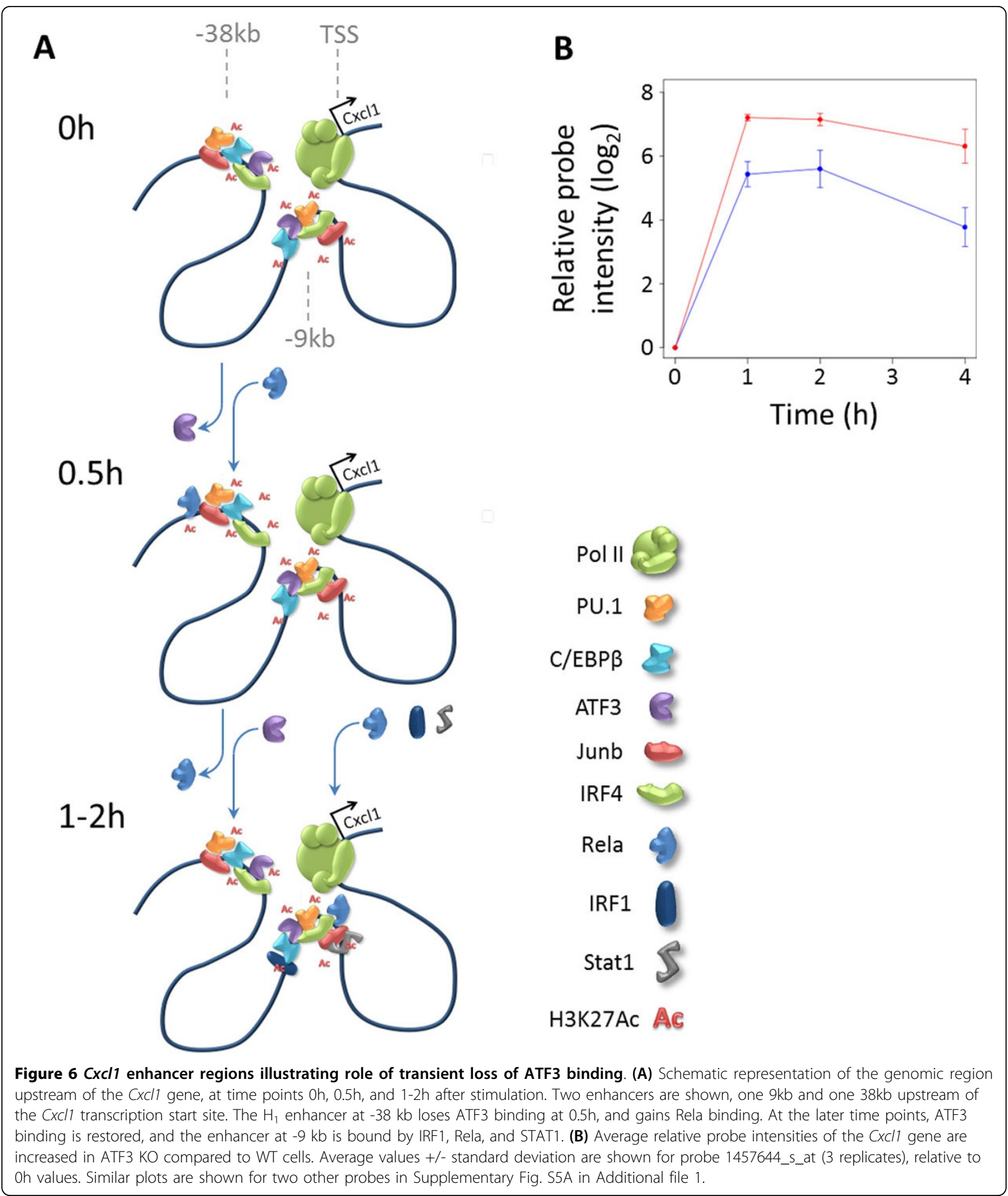

have a tendency to be already enriched for binding by Rela compared to regions where no binding by ATF3 occurs. These regions, too, have an additional increase in Rela binding following the transition to class $\mathrm{H} 1$. Similarly, $\mathrm{H}_{3}$ regions changing to class $\mathrm{H}_{1}$ have a higher tendency to be bound by IRF1 compared to $\mathrm{H}_{3}$ regions lacking a transition to $\mathrm{H}_{1}$ (Figure 7A). These findings suggest a certain interaction between binding of Rela and/or IRF1 and binding of ATF3, and the formation of a $\mathrm{H}_{1}$ type environment. 


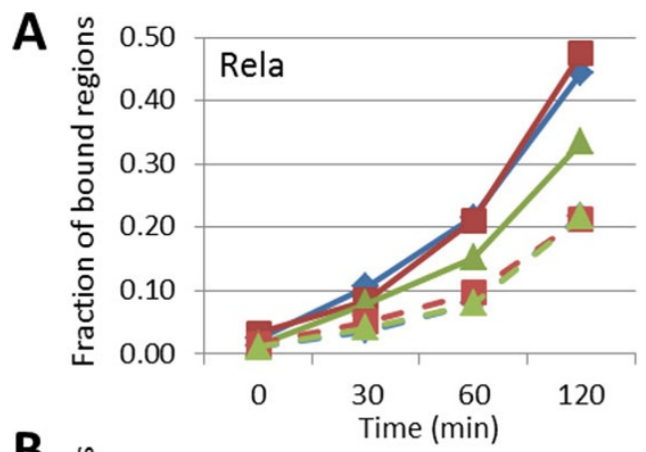

B

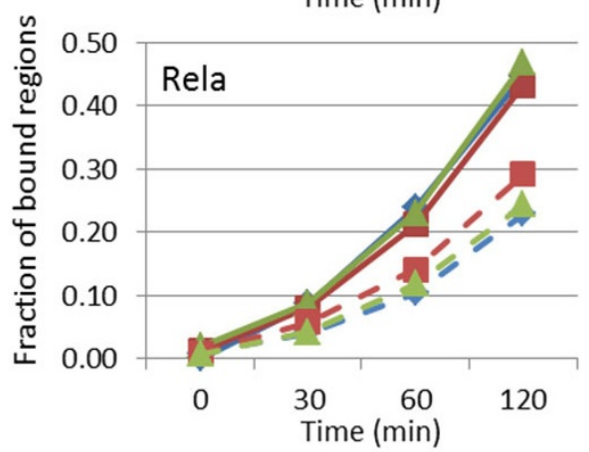

class transition

- between 0 and $30 \mathrm{~min}$.

- between 30 and $60 \mathrm{~min}$.

- between 60 and $120 \mathrm{~min}$.
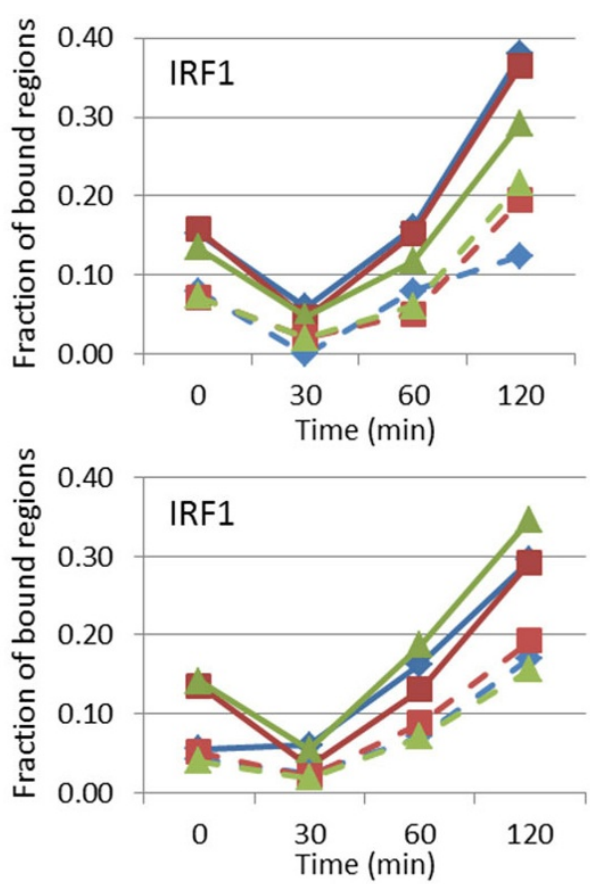

no class transition

- - between 0 and $30 \mathrm{~min}$.

- - between 30 and $60 \mathrm{~min}$.

- - between 60 and $120 \mathrm{~min}$.

C

Between 0 and 30 mins.

to

\begin{tabular}{|c|c|c|c|c|c|c|c|c|c|c|c|c|c|c|}
\hline & $\mathbf{H}_{1}$ & $\mathrm{H}_{2}$ & $\mathrm{H}_{3}$ & $M_{1}$ & $M_{2}$ & $M_{3}$ & $L_{1}$ & $\mathrm{~L}_{2}$ & $\mathrm{~L}_{3}$ & $\mathrm{~L}_{4}$ & $C_{1}$ & $C_{2}$ & $C_{3}$ & \\
\hline $\mathrm{H}_{1}$ & $\mathrm{H}_{1}$ & $\mathrm{H}_{2}$ & $\mathrm{H}_{3}$ & $\mathrm{C}_{2}$ & $\mathrm{M}_{2}$ & $\mathrm{M}_{3}$ & & & & & $C_{1}$ & & & 35 \\
\hline $\mathrm{H}_{2}$ & $\mathrm{H}_{1}$ & $\mathrm{H}_{2}$ & $\mathrm{H}_{3}$ & & $\mathrm{M}_{2}$ & $\mathrm{C}_{3}$ & & $\mathrm{~L}_{2}$ & $\mathrm{~L}_{3}$ & & $C_{3}$ & & & 30 \\
\hline $\mathbf{H}_{3}$ & $\mathrm{H}_{1}$ & $\mathrm{H}_{2}$ & $\mathrm{H}_{3}$ & $\mathrm{M}_{1}$ & $\mathrm{M}_{2}$ & $\mathrm{M}_{3}$ & $\mathrm{~L}_{1}$ & $\mathrm{M}_{2}$ & & & & & & 30 \\
\hline$M_{1}$ & $\mathrm{H}_{1}$ & & $\mathrm{H}_{3}$ & $\mathrm{M}_{1}$ & $\mathrm{M}_{2}$ & $\mathrm{M}_{3}$ & $\mathrm{~L}_{1}$ & & $\mathrm{H}_{1}$ & & & & & 25 \\
\hline $\mathrm{M}_{2}$ & & $\mathrm{H}_{2}$ & $\mathrm{H}_{3}$ & $\mathrm{~L}_{1}$ & $\mathrm{M}_{2}$ & $\mathrm{M}_{3}$ & $\mathrm{~L}_{1}$ & $\mathrm{~L}_{2}$ & $\mathrm{~L}_{3}$ & & & & & \\
\hline$M_{3}$ & & $\mathrm{H}_{2}$ & $\mathrm{H}_{3}$ & & $\mathrm{M}_{2}$ & $\mathrm{M}_{3}$ & $\mathrm{~L}_{1}$ & $\mathrm{~L}_{2}$ & & $\mathrm{~L}_{4}$ & & & & \\
\hline $\mathrm{L}_{1}$ & & & & $\mathrm{M}_{1}$ & $\mathrm{M}_{2}$ & $\mathrm{M}_{3}$ & $\mathrm{~L}_{1}$ & $\mathrm{~L}_{2}$ & $L_{3}$ & $\mathrm{~L}_{4}$ & & & & \\
\hline$L_{2}$ & & $\mathrm{H}_{2}$ & & & & $\mathrm{M}_{3}$ & $\mathrm{H}_{2}$ & $\mathrm{~L}_{2}$ & $\mathrm{~L}_{3}$ & $\mathrm{~L}_{4}$ & & & & \\
\hline$L_{3}$ & & $C_{1}$ & & & $\mathrm{M}_{2}$ & & $\mathrm{~L}_{1}$ & $M_{3}$ & $L_{3}$ & $\mathrm{~L}_{4}$ & & & & \\
\hline $\mathrm{L}_{4}$ & & & & & & $\mathrm{H}_{3}$ & $\mathrm{~L}_{1}$ & $\mathrm{~L}_{2}$ & $\mathrm{~L}_{3}$ & $\mathrm{~L}_{4}$ & & & $\mathrm{C}_{3}$ & 5 \\
\hline$C_{1}$ & $\mathrm{H}_{1}$ & & $\mathrm{H}_{3}$ & & & & & & & & $C_{1}$ & $C_{2}$ & & \\
\hline$C_{2}$ & & & & & $M_{2}$ & $\mathrm{M}_{3}$ & $M_{1}$ & & & & $\mathrm{H}_{1}$ & $C_{2}$ & $\mathrm{M}_{3}$ & 0 \\
\hline$C_{3}$ & & & & & & & & & & $\mathrm{~L}_{4}$ & $C_{1}$ & $\mathrm{H}_{1}$ & $C_{3}$ & NA \\
\hline
\end{tabular}

Figure 7 Role of activated TFs and inter-enhancer interactions in TF binding changes after LPS stimulation. (A) Two plots show the fraction of $\mathrm{H}_{3}$ regions bound by Rela and IRF1, respectively. Solid lines represent $\mathrm{H}_{3}$ regions switching to class $\mathrm{H}_{1}$ before 30 mins. (blue), before 60 mins. (red) and before 120 mins. (green) after stimulation. Dotted lines are for $\mathrm{H}_{3}$ regions not making a change between these time points.

(B) Same as in (A) for $\mathrm{H}_{2}$ regions changing (or not changing) to class H1. (C) Table summarizing the positional biases between enhancers changing from one class (rows) to another (columns) between time points $0 \mathrm{~h}$ and $0.5 \mathrm{~h}$. For each pair of classes, the enhancer class located most closely to the changing enhancers is shown. The colour code represents t-test $\mathrm{p}$ values. The same tables for time points $0.5 \mathrm{~h}$ to $1 \mathrm{~h}$ and $1 \mathrm{~h}$ to $2 \mathrm{~h}$ are shown in Supplementary Fig. $\mathrm{S} 6$ in Additional file 1. 
Similar results were obtained for class $\mathrm{H}_{2}$ regions changing to class $\mathrm{H}_{1}$ (Figure 7B). In addition, enhancers of classes $\mathrm{H}_{2}$ and $\mathrm{H}_{3}$ that switch to $\mathrm{H}_{1}$ tend to have relatively higher binding by Maff even before stimulation and before making the class transition (data not shown), and later on these regions show relatively high binding by Rel, Relb, Runx1, E2F1, and Egr2, and after 2 hours additional binding by STAT family members. Similar changes were also observed for other time points, and on a smaller scale for regions of other classes changing to class $\mathrm{H} 1$.

These observations further underline the importance of the binding pattern of enhancers of class $\mathrm{H}_{1}$, consisting of binding by PU.1, C/EBP $\beta$, JunB, ATF3, and IRF4, which form together an environment that can easily be bound by several other TFS, including TFs that are activated following stimulation, such as NF- $\kappa$ B and STAT family members. The coincidence of binding changes at certain points following stimulation also suggests a certain degree of mutual influence or cooperativity between TFs.

\section{Nearby enhancers influence enhancer class dynamics following stimulation}

The existence of interactions between distal elements through looping is widely recognized. Several studies have described interactions, through looping, between promoters and distal sites, including enhancers $[23,26]$. However, interactions between pairs of enhancers, and their potential functions, are often ignored. In a final step, we evaluated whether proximally located enhancers might influence the binding of TFs after stimulation, and in particular how this might affect the formation of enhancers of class $\mathrm{H}_{1}$.

For each enhancer we calculated the distance to the most proximally located enhancer of each class, for each time point before and after stimulation. We picked up enhancers with a transition to a different class between time points, and compared the distances to each class of enhancers. We did the same for enhancers that did not have a transition to a different class. Finally, we compared the two sets of distances using a t-test.

In general, we found that enhancers changing to a certain class " $\mathrm{X}$ ", tend to be located relatively proximally to an existing enhancer of class " $X$ " (Figure $7 C$ and Supplementary Fig. S8 in Additional file 1). For example, enhancers of class $\mathrm{H}_{1}$ that change to class $\mathrm{H}_{3}$ between time points 0 and 30 mins. tend to be more closely located to already existing enhancers of class $\mathrm{H}_{3}$ (median distance $49.4 \mathrm{~kb}$ vs $72.2 \mathrm{~kb}$, t-test based p value: $3.8 \mathrm{e}-15$ ). Similarly, between 30 and 60 mins. after stimulation, $\mathrm{H}_{1}$ enhancers switching to $\mathrm{H}_{2}$ are located more proximally to existing $\mathrm{H}_{2}$ enhancers (median distance $31.1 \mathrm{~kb}$ vs $45.2 \mathrm{~kb}$, t-test based p value: 1.9e-10). Finally, between 60 and 120 mins. after stimulation, a large fraction of $\mathrm{H}_{2}$ enhancers change to $\mathrm{H}_{1}$ enhancers. These $\mathrm{H}_{2}$ enhancers tend to be located proximally to existing $\mathrm{H}_{1}$ enhancers (median distance $29.4 \mathrm{~kb}$ vs $50.0 \mathrm{~kb}$, t-test based p value: $1.2 \mathrm{e}-35$ ).

Based on the assumption that proximally located enhancer pairs are more likely to be interacting than distally located ones, these results suggest that the presence of enhancers belonging to one particular class make nearby enhancers more likely to change to that same class. In other words, the TFs binding to an enhancer can be influenced by TFs bound to surrounding enhancers. In the case of $\mathrm{H}_{1}$ enhancers, the existence of $\mathrm{H}_{1}$ enhancers can induce nearby enhancers to gain binding by principal TFs and to thus become $\mathrm{H}_{1}$ enhancers, a process that is aided by the activation and binding of specific TFs following stimulation (see previous section).

\section{Conclusions}

In this integrative analysis we used newly obtained RNAseq and TSS data in combination with publicly available data sets to address several questions concerning the features and dynamics of enhancers, in particular, variations in the sets of TFs binding their functional role in the regulation of transcription following stimulation, and the dynamics in binding by TFs following stimulation. For this we employed a set of datasets from myeloid APCs, allowing us to identify enhancer regions. We initially classified enhancer regions according to the TFs binding to them before stimulation, and we found a number of different enhancer classes, each defined by a different set of binding regulators. Although many regions appeared to be bound by PU.1 and C/EBP $\beta$, several classes lacked one or even both of these regulators. Importantly, there was a strong association between genes that are induced upon LPS stimulation and a class of enhancers that are bound by PU.1, C/EBP $\beta$, ATF3, IRF4, and JunB ( $\mathrm{H}_{1}$ enhancers).

Interestingly, key regulators of the transcriptional response to LPS stimulation, such as NF- $\kappa \mathrm{B}$, IRFs, and STAT family TFs, bind preferentially to these $\mathrm{H}_{1}$ enhancer regions after stimulation. Moreover, following stimulation, there was considerable dynamics in the binding of enhancers by the principal TFs, and we observed that the acquisition of a class $\mathrm{H}_{1}$ enhancer binding profile tends to cooccur with the binding of NF- $\kappa \mathrm{B}$ subunits, especially Rela. This suggests that the TFs bound by class $\mathrm{H}_{1}$ enhancers create a local environment that facilitates the binding of activated TFs, and that activated TFs contribute in the creation of this environment. Regulators that are activated at later time points, such as the STAT family TFs, also tend to favour binding to the class $\mathrm{H}_{1}$ enhancers.

In addition to the influence of activated TFs, our results suggest that regions with similar sets of bound TFs (such as class $\mathrm{H}_{2}$ enhancers, bound by PU.1, C/EBP $\beta$, ATF3, JunB but not IRF4; and class $\mathrm{H}_{3}$ enhancers, bound by PU.1, C/EBP $\beta$, IRF4, JunB but not ATF3) 
tend to gain IRF4 or ATF3 binding especially when they are located relatively proximally to existing class $\mathrm{H}_{1}$ enhancers. This too supports the existence of a local environment with increased TF binding, which might easily influence nearby enhancers, for example through looping of the DNA.

Together, our results suggest that genes can be marked for rapid induction even before stimulation by specific combinations of TFs binding to nearby enhancers, allowing for rapid initiation of transcription following stimulation. However, several levels of regulation appear to be present after stimulation, including interactions between proximally located pairs of enhancers. Such interactions might influence the induction time or stability of transcription of nearby genes, which are important factors in the response against pathogens. Future analyses using Carbon-Copy Chromosome Conformation Capture (5C) or related techniques will be necessary to further investigate the interactions between enhancers with particular TF binding profiles and their changes over time.

Our results confirmed that a large fraction of regions with enhancer-like features in myeloid APCs are bound by PU.1 and C/EBP $\beta$, as has recently been reported $[8,9,11]$. However, we showed that the specific properties of the enhancers are defined by the specific subset of TFs binding to them, even before stimulation. Our integrative study underscores the importance of detailed analysis of highthroughput sequencing data and how it can reveal findings that are obscured when averaging over all enhancers.

\section{Additional material}

Additional file 1: Supplementary material - (PDF file). File containing description of supporting analyses as well as supplementary tables and figures.

\author{
List of abbreviations used \\ APC antigen presenting cell \\ BMDC bone marrow-derived dendritic cell \\ BMDM bone marrow-derived macrophage \\ DC dendritic cell \\ DDBJ DNA Data Bank of Japan \\ KO knock-out \\ LPS lipopolysaccharide \\ Pol2 RNA polymerase ॥ \\ RPKM reads per kilobase per million reads \\ TF transcription factor \\ TSS transcription start site \\ WT wild-type
}

\section{Competing interests}

The authors declare that they have no competing interests.

\section{Authors' contributions}

AV carried out data processing and bioinformatics analysis. ST and DMS participated in the bioinformatics analysis and helped to draft the manuscript. OT and YS prepared biological samples and sequencing data, and assisted in the analysis and interpretation of data. All authors read and approved the final manuscript.

\section{Acknowledgements}

The authors thank all members of the laboratory of Systems Immunology and Dr. Damien Hall and Dr. Diego Diez for helpful discussions and advice; and M. Ogawa for secretarial assistance.

Funding: This work was supported by the Special Coordination Funds of the Japanese Ministry of Education, Culture, Sports, Science and Technology, and the Ministry of Health, Labour and Welfare in Japan; the Japan Society for the Promotion of Science through Funding Program for World-Leading Innovative R\&D on Science and Technology (FIRST Program); and by a Kakenhi Grant-in-Aid for Scientific Research (23710234 to AV) from the Japan Society for the Promotion of Science.

\section{Declarations}

Publication costs for this article were funded by the corresponding authors' institution.

This article has been published as part of BMC Genomics Volume 15 Supplement 10, 2014: Proceedings of the 25th International Conference on Genome Informatics (GIW/ISCB-Asia): Genomics. The full contents of the supplement are available online at http://www.biomedcentral.com/ bmcgenomics/supplements/15/S10.

\section{Authors' details}

'Laboratory of Systems Immunology, Immunology Frontier Research Center Osaka University, Suita, 565-0871, Japan. ${ }^{2}$ Immuno-Genomics Research Unit, Immunology Frontier Research Center, Osaka University, Suita, 565-0871, Japan. ${ }^{3}$ Quantitative Immunology Research Unit, Immunology Frontier Research Center, Osaka University, Suita, 565-0871, Japan. ${ }^{4}$ Laboratory of Infection and Prevention, Institute for Virus Research, Kyoto University, Kyoto, 606-8507, Japan. ${ }^{5}$ Department of Medical Genome Sciences, Graduate School of Frontier Sciences, The University of Tokyo, Kashiwa, 277-8568, Japan.

Published: 12 December 2014

References

1. Lenhard B, Sandelin A, Carninci P: Metazoan promoters: emerging characteristics and insights into transcriptional regulation. Nat Rev Genet 2012, 13:233-45.

2. Ong $C T$, Corces VG: Enhancer function: new insights into the regulation of tissue-specific gene expression. Nat Rev Genet 2011, 12:283-93.

3. Spitz F, Furlong EEM: Transcription factors: from enhancer binding to developmental control. Nat Rev Genet 2012, 13:613-26.

4. Barski A, Cuddapah S, Cui K, Roh TY, Schones DE, Wang Z, Wei G, Chepelev I, Zhao K: High-resolution profiling of histone methylations in the human genome. Cell 2007, 129:823-37.

5. Heintzman ND, Stuart RK, Hon G, Fu Y, Ching CW, Hawkins RD, Barrera LO Van Calcar S, Qu C, Ching Ka, Wang W, Weng Z, Green RD, Crawford GE, Ren B: Distinct and predictive chromatin signatures of transcriptional promoters and enhancers in the human genome. Nat Genet 2007 39:311-8.

6. Dunham I, Kundaje A, Aldred SF, Collins PJ, Davis Ca, Doyle F, Epstein CB, Frietze S, Harrow J, Kaul R, Khatun J, Lajoie BR, Landt SG, Lee BK, Pauli F, Rosenbloom KR, Sabo P, Safi A, Sanyal A, Shoresh N, Simon JM, Song L, Trinklein ND, Altshuler RC, Birney E, Brown JB, Cheng C, Djebali S, Dong X, Ernst J, et al: An integrated encyclopedia of DNA elements in the human genome. Nature 2012, 489:57-74.

7. Shen Y, Yue F, McCleary DF, Ye Z, Edsall L, Kuan S, Wagner U, Dixon J, Lee $L$, Lobanenkov $W$, Ren $B$ : A map of the cis-regulatory sequences in the mouse genome. Nature 2012, 488:116-20.

8. Ghisletti S, Barozzi I, Mietton F, Polletti S, De Santa F, Venturini E, Gregory L, Lonie L, Chew A, Wei CL, Ragoussis J, Natoli G: Identification and characterization of enhancers controlling the inflammatory gene expression program in macrophages. Immunity 2010, 32:317-28.

9. Heinz S, Benner C, Spann N, Bertolino E, Lin YC, Laslo P, Cheng JX, Murre C, Singh $H$, Glass CK: Simple combinations of lineage-determining transcription factors prime cis-regulatory elements required for macrophage and B cell identities. Mol Cell 2010, 38:576-89. 
10. Ostuni R, Piccolo V, Barozzi I, Polletti S, Termanini A, Bonifacio S, Curina A, Prosperini E, Ghisletti S, Natoli G: Latent enhancers activated by stimulation in differentiated cells. Cell 2013, 152:157-71.

11. Garber M, Yosef N, Goren A, Raychowdhury R, Thielke A, Guttman M, Robinson J, Minie B, Chevrier N, Itzhaki Z, Blecher-Gonen R, Bornstein C, Amann-Zalcenstein D, Weiner A, Friedrich D, Meldrim J, Ram O, Cheng C, Gnirke A, Fisher S, Friedman N, Wong B, Bernstein BE, Nusbaum C, Hacohen N, Regev A, Amit I: A High-Throughput Chromatin Immunoprecipitation Approach Reveals Principles of Dynamic Gene Regulation in Mammals. Mol Cell 2012, 47:810-22.

12. Tsuchihara $K$, Suzuki $Y$, Wakaguri $H$, Irie T, Tanimoto K, Hashimoto $S$, Matsushima K, Mizushima-Sugano J, Yamashita R, Nakai K, Bentley D, Esumi H, Sugano S: Massive transcriptional start site analysis of human genes in hypoxia cells. Nucleic Acids Res 2009, 37:2249-63.

13. De Santa F, Narang V, Yap ZH, Tusi BK, Burgold T, Austenaa L, Bucci G, Caganova M, Notarbartolo S, Casola S, Testa G, Sung WK, Wei CL, Natoli G: Jmjd3 contributes to the control of gene expression in LPS-activated macrophages. EMBO J 2009, 28:3341-52.

14. Cox AJ: ELAND: Efficient Large-Scale Alignment of Nucleotide Databases. San Diego, CA: Illumina; 2007.

15. Li R, Yu C, Li Y, Lam TW, Yiu SM, Kristiansen K, Wang J: SOAP2: an improved ultrafast tool for short read alignment. Bioinformatics 2009, 25:1966-7.

16. Hoskins RA, Landolin JM, Brown JB, Sandler JE, Takahashi H, Lassmann T, Yu C, Booth BW, Zhang D, Wan KH, Yang L, Boley N, Andrews J, Kaufman TC, Graveley BR, Bickel PJ, Carninci P, Carlson JW, Celniker SE: Genome- wide analysis of promoter architecture in Drosophila melanogaster. Genome Res 2011, 21:182-192.

17. Mercer TR, Wilhelm D, Dinger ME, Soldà G, Korbie DJ, Glazov Ea, Truong V, Schwenke M, Simons C, Matthaei KI, Saint R, Koopman P, Mattick JS: Expression of distinct RNAs from $3^{\prime}$ untranslated regions. Nucleic Acids Res 2011, 39:2393-403.

18. Meyer LR, Zweig AS, Hinrichs AS, Karolchik D, Kuhn RM, Wong M, Sloan Ca, Rosenbloom KR, Roe G, Rhead B, Raney BJ, Pohl A, Malladi VS, Li CH, Lee BT, Learned K, Kirkup V, Hsu F, Heitner S, Harte Ra, Haeussler M, Guruvadoo L, Goldman M, Giardine BM, Fujita Pa, Dreszer TR, Diekhans M, Cline MS, Clawson H, Barber GP, et al: The UCSC Genome Browser database: extensions and updates 2013. Nucleic Acids Res 2013, 41(Database):D64-9.

19. Pruitt KD, Tatusova T, Brown GR, Maglott DR: NCBI Reference Sequences (RefSeq): current status, new features and genome annotation policy. Nucleic Acids Res 2012, 40(Database):D130-5.

20. Tibshirani $R$, Walther $G$, Hastie $T$ : Estimating the number of clusters in a data set via the gap statistic. J R Stat Soc Ser B (Statistical Methodol) 2001, 63:411-423.

21. Rustici G, Kolesnikov N, Brandizi M, Burdett T, Dylag M, Emam I, Farne A, Hastings E, Ison J, Keays M, Kurbatova N, Malone J, Mani R, Mupo A, Pedro Pereira R, Pilicheva E, Rung J, Sharma A, Tang YA, Ternent T, Tikhonov A, Welter D, Williams E, Brazma A, Parkinson H, Sarkans U: ArrayExpress update-trends in database growth and links to data analysis tools. Nucleic Acids Res 2013, 41(Database):D987-90.

22. Chepelev I, Wei G, Wangsa D, Tang Q, Zhao K: Characterization of genome-wide enhancer-promoter interactions reveals co-expression of interacting genes and modes of higher order chromatin organization. Cell Res 2012, 22:490-503.

23. Sanyal A, Lajoie BR, Jain G, Dekker J: The long-range interaction landscape of gene promoters. Nature 2012, 489:109-113.

24. Ritzman AM, Hughes-Hanks JM, Blaho V a, Wax LE, Mitchell WJ, Brown CR: The chemokine receptor CXCR2 ligand KC (CXCL1) mediates neutrophil recruitment and is critical for development of experimental Lyme arthritis and carditis. Infect Immun 2010, 78:4593-600.

25. Gilchrist M, Thorsson V, Li B, Rust AG, Korb M, Roach JC, Kennedy K, Hai T, Bolouri H, Aderem A: Systems biology approaches identify ATF3 as a negative regulator of Toll-like receptor 4. Nature 2006, 441:173-8.

26. Lieberman-Aiden E, van Berkum NL, Williams L, Imakaev M, Ragoczy T, Telling A, Amit I, Lajoie BR, Sabo PJ, Dorschner MO, Sandstrom R, Bernstein B, Bender Ma, Groudine M, Gnirke A, Stamatoyannopoulos J, Mirny La, Lander ES, Dekker J: Comprehensive mapping of long-range interactions reveals folding principles of the human genome. Science 2009, 326:289-93.
doi:10.1186/1471-2164-15-S10-S4

Cite this article as: Vandenbon et al: Dynamics of enhancers in myeloid antigen presenting cells upon LPS stimulation. BMC Genomics 2014 15(Suppl 10):S4.

\section{Submit your next manuscript to BioMed Central and take full advantage of:}

- Convenient online submission

- Thorough peer review

- No space constraints or color figure charges

- Immediate publication on acceptance

- Inclusion in PubMed, CAS, Scopus and Google Scholar

- Research which is freely available for redistribution 